\title{
Authors' Reply: 18F-fluorocholine PET/CT in MEN1 Patients with Primary Hyperparathyroidism
}

\author{
Sébastien Gaujoux ${ }^{1}$ Mathieu Gauthé ${ }^{2}$ (D) Lionel Groussin $^{1}$
}

Accepted: 27 November 2020/Published online: 1 January 2021

(C) Société Internationale de Chirurgie 2021

\section{Dear Editor,}

We read with interest the comment to our recently published article "18F-fluorocholine PET/CT in MEN1 Patients with Primary Hyperparathyroidism."

The ultimate goal of MEN1 primary hyperparathyroidism management is to provide patients with a quality of life, i.e., avoiding definitive hypoparathyroidism and reducing the surgical burden of reoperation, comparable to the general population and in the same time protecting them against the long-term effect of hypercalcemia. With this in mind, surgery should aim to normal parathyroid hormone serum level, not only in the early postoperative period, but on the long term. This is challenging, in young operated patients, as underlines by Barnes, since in MEN1 parathyroid hyperplasia involves all four parathyroid glands which may eventually become adenomatous at different times, according to the Hudson two-hit theory.

As Barnes, we strongly believe that optimal preoperative location of pathologic or the most pathologic glands is key in the surgical management of these patients. If the gold standard of MEN1 primary hyperparathyroidism treatment remains subtotal parathyroidectomy, nowadays, less invasive, i.e., unilateral neck exploration, minimally invasive parathyroidectomy is considered by some team, as demonstrated by a recent paper [1]. In order to better evaluate such practice, this calls us for better national and international collaboration, the only way to produce highlevel evidence on such a rare and heterogeneous disease.

\section{Reference}

1. Choi HR, Choi SH, Choi SM, Kim JK, Lee CR, Kang SW et al (2020) Benefit of diverse surgical approach on short-term outcomes of MEN1-related hyperparathyroidism. Sci Rep 10(1):10634

Publisher's Note Springer Nature remains neutral with regard to jurisdictional claims in published maps and institutional affiliations.

Mathieu Gauthé

mathieugauthe@yahoo.fr

1 Hopital Cochin - Université de Paris, Paris, France

2 Hopital Tenon - Sorbonne Université, Paris, France 